\title{
Autologous stem cell transplant program in 2016-country report from Bangladesh
}

\author{
Mafruha Akter ${ }^{1}$, Mohiuddin Ahmed Khan ${ }^{1}$, Bimalangshu R Dey ${ }^{2}$ \\ ${ }^{1}$ BMT Unit, Department of Hematology, Dhaka Medical College Hospital (DMCH), ${ }^{2}$ Massachusetts General Hospital \\ $(\mathrm{MGH})$, Harvard Medical School, Boston, USA
}

\section{Abstract}

We are describing eleven autologous hematopoietic stem cell transplants (ASCT) that were performed in 2016 at three different transplant centers in Bangladesh. Indications for those patients were multiple myeloma (MM) $(n=4)$, diffuse large B cell lymphoma (DLBCL) $(n=2)$, Hodgkin's lymphoma (HD) $(n=2)$, peripheral T cell lymphoma (PTCL) $(n=1)$, acute myeloid leukemia $(A M L)(n=1)$, and acute promyelocytic leukemia $(A P L)(n=1)$. All autologous stem cell products were cryo-preserved and transfused back to patients freshly thawed at $37^{\circ} \mathrm{C}$. All were in second remission (CR2) except for the PTCL patient, who was in first remission (CR1). The bone marrow transplant (BMT) program was first initiated in Bangladesh in March 2014 at the Dhaka Medical College Hospital $(\mathrm{DMCH})$, the country's largest and the leading government-run public hospital, in collaboration with the Massachusetts General Hospital in Boston, USA. Subsequently, two more centers, Apollo Hospitals Dhaka and the Combined Military Hospital (CMH), started transplant programs in 2016. Seven out of eleven ASCT were performed at the DMCH center, with two at Apollo Hospitals and two at $\mathrm{CMH}$ Dhaka. The median age for all patients was 39 (range 18-67) and the Male: Female ratio was 9: 2. The average time to neutrophil and platelet engraftment was day 9 (range 8-12) and day 12 (range 9-15), respectively. Major early complications were neutropenic fever, mucositis, and infection. There was no transplant related mortality (TRM) within the first 100 days. Over a median follow up of 2 years, overall survival is $82.0 \%$ and progression free survival is $63.6 \%$.

Key words: Hematopoietic stem cell transplantation, Transplant related mortality

Submitted May 27, 2019; Accepted November 18, 2019; Published online February 25, 2020; Issued online February 25, 2020 Correspondence: Mafruha Akter, BMT Unit, Department of Hematology, Dhaka Medical College Hospital (DMCH), Secretariat Rd, Dhaka 1000, Bangladesh, E-mail: mafruha673@gmail.com

\section{First establishment of transplant center at $\mathrm{DMCH}$ in Bangladesh}

Bangladesh is known to be a densely populated country with a population over 160 million. Although it has no population-based cancer prevalence registry, a number of hospital-based retrospective analyses reported that Acute myeloid leukemia (AML), malignant lymphoma (both Hodgkin's and non-Hodgkin's), and multiple myeloma (MM) are the leading hematological malignancies in the adult age group in our country ${ }^{1}$. In addition, transfusiondependent thalassemia is a silent burden as evidenced by the World Health Organization (WHO) report that estimates that approximately $7 \%$ of total population are carriers of either beta-thalassemia or hemoglobin $\mathrm{E}(\mathrm{HbE})$ in Bangladesh ${ }^{2}$. It is estimated that nearly 2,500 thalas- semia major cases are added every year in Bangladesh ${ }^{3}$ that could potentially be cured by allogeneic stem cell transplantation. Over $70 \%$ of the population lives in resource-limited rural areas and these people are not able to afford the standard treatment for health-related problems, including cancer treatment. Although the number of eligible patients for both autologous and allogeneic transplant is rising, only a very small proportion of them can afford the highly expensive hematopoietic stem cell transplantation (HSCT). In the past, most patients who could afford to pay for treatment went abroad for transplant because of the unavailability of transplant services prior to 2014.

Prof MA Khan, was inspired to start a transplant program in Bangladesh while attending a workshop in Vietnam organized by Asia-Pacific Blood ang Marrow Trans- 
plantation Group (APBMT) and Worldwide Network for Blood and Marrow Transplantation (WBMT) in 2011. Later, under his key leadership and encouragement, Bangladesh started the HSCT journey. The first autologous transplant was completed successfully for a MM patient on March 10, 2014, at the pioneer HSCT center in Bangladesh, the Dhaka Medical College Hospital (DMCH), which has a collaborative partnership with the Bangladesh government and the Massachusetts General Hospital (MGH) in Boston, USA. The initial goal of the collaboration was to build a comprehensive program and a center of excellence for hematologic malignancies. The most important and crucial steps for establishing a stem cell transplant center were: (1) establishment and signing of a bilateral Memorandum of Understanding (MOU) between $\mathrm{DMCH}$ and $\mathrm{MGH},(2)$ appropriate infrastructure development, (3) human resource capacity building to make a core clinical team for transplant program, and (4) financial considerations ${ }^{4}$.

In 2012, an MOU was signed between the Ministry of Health and Family Welfare (MOHFW) and MGH, incorporating the exchange of faculty and nursing staff and promoting capacity building activities. All of the funding was provided by the Government of Bangladesh. The first ever BMT unit was established on the top floor of a newly built ten-story building, DMCH-2. The structural and mechanical design was adopted and supported by MGH. Critical components of a functioning transplantation program include basic infrastructure and sanitation as well as standard protocols for stem cell mobilization, transplant processes, transfusion medicine, and diagnostics. Each aspect of construction, progress, and development was critically observed by a respective team with the objective to ensure the best care for sick patients. Finally, in 2013, a third-party inspection was conducted by a transplant physician team led by India. According to their suggestions and recommendations, additional modifications were made to complete the functioning HSCT unit. To elevate the clinical competencies and professional status of the nurses in the newly established unit, a comprehensive curriculum for the care of transplant patients was developed by nurses and nurse practitioners at MGH and the Simmons College School of Nursing and Health Sciences 5 .

The HSCT unit of DMCH is approximately 7,000 square feet and includes 5 private inpatient rooms with HEPA filtration, a separate apheresis area, an irradiator for blood products, a stem cell processing laboratory and general hematology labs, a flow cytometry lab, a separate pharmacy, and shared inpatient rooms for receiving highdose chemotherapy. As of February 2019, 40 autologous stem cell transplantations have been completed successfully at the DMCH center without any transplant-related mortality (TRM) in the first 100 days. The auto transplant cost in Bangladesh is relatively low for the first 100 days and varies from $\$ 7,000-\$ 10,000$ compared to that of around $\$ 100,000$ in the $\mathrm{USA}^{6}$.

\section{Patients and Methods}

We retrospectively analyzed patient data for eleven auto transplants from three different centers in Bangladesh in 2016. No allogeneic transplant was performed in 2016 in any of these centers.

\section{Results: Current HSCT activity of three centers in 2016}

In 2016, in addition to DMCH, two more centers, the private Apollo Hospitals Dhaka and the Combined Military Hospital (CMH) Dhaka developed transplant programs with autologous transplant. A total of 11 autologous stem cell transplantations were performed by these three centers. All auto transplants were from peripheral blood stem cell transplantation (PBSCT). Among them 4 were MM, 3 were non-Hodgkin lymphoma (NHL), 3 were Hodgkin disease (HD), 1 was AML, and 1 was acute promyelocytic leukemia (APL). Seven auto transplants for different indications (3 NHL, $2 \mathrm{HD}, 1 \mathrm{AML}$, and 1 APL) were performed by DMCH. Apollo Hospitals and $\mathrm{CMH}$ also successfully performed two MM cases, each as a new center in 2016. All except the PTCL patient were in CR2 before transplant. The median age for all patients was 39 (range 18-67) and the Male: Female ratio was 9: 2. Average neutrophil and platelet engraftment were on day 9 and day 12, respectively (Table 1). Major early complications were neutropenic fever, mucositis, and infection (Figure 1). Four (36.6\%) patients had positive bacterial culture (coagulase neg staph epidermidis, pseudomonas sp, and Klebsiella sp) in blood or urine. There was no TRM within the first 100 days in any center. Four patients relapsed, among them 2 are alive with metronomic therapy and 2 died a few days after relapse. Over a median follow up of two years, calculated up to December 2018, overall survival (OS) is $82.0 \%$ and progression free survival (PFS) is 63.6\% (Figure 2, Table 2).

\section{National data registry}

Currently there is no formal national registry for collecting activity survey data and outcome registry data in our country. Each center maintains data independently. The data collection system is person-based. One physician has been appointed as a registry committee member of APBMT on behalf of Bangladesh. This physician collects the basic data from all three transplant centers and submits the APBMT activity survey. We plan to develop a national BMT registry in the near future to collect trans- 
Table 1. Demographic and clinical data of all patients

\begin{tabular}{|c|c|c|}
\hline Characteristics & Autologous transplant & Others features \\
\hline Total number & $\mathrm{N}: 11$ & \\
\hline $\begin{array}{l}\text { Age median } \\
\text { (range) }\end{array}$ & $39(18-67)$ years old & \\
\hline Male: Female & 9: 2 & \\
\hline \multirow[t]{7}{*}{ Indication } & & Conditioning: \\
\hline & Multiple Myeloma on CR2: 4 & High dose Melphalan \\
\hline & DLBCL on CR2: 2 & BEAM \\
\hline & Hodgkin's Disease on CR2: 2 & BEAM \\
\hline & PTCL on CR1: 1 & BEAM \\
\hline & AML on CR2: 1 & $\mathrm{Bu}-\mathrm{Cy}$ \\
\hline & APL on CR2: 1 & Bu-Cy \\
\hline Stem cell source & Autologous peripheral blood stem cell: 11 & \\
\hline Average stem cell dose (range) & $2.93 \times 10^{6} / \mathrm{kg}\left(2.33-3.65 \times 10^{6} / \mathrm{kg}\right)$ & \\
\hline $\begin{array}{l}\text { Stem cell mobilization protocol: } \\
\text { Chemo followed by GCSF } \\
\text { GCSF+Plerixafor } \\
\text { Only GCSF }\end{array}$ & $\begin{array}{l}7 \\
2 \\
2\end{array}$ & $\begin{array}{l}\text { All the products were cryo-pre- } \\
\text { served and given to patients } \\
\text { freshly thawed at } 37^{\circ} \mathrm{C} \text {. }\end{array}$ \\
\hline \multicolumn{3}{|l|}{ Engraftment in days } \\
\hline Neutrophil & Day $9(8-12)$ & \\
\hline Platelet & Day 12 (9-15) & \\
\hline Average hospital stay (range) & 19 days $(18-28)$ & \\
\hline 100 days post-transplant outcome & $100 \%$ alive and in $\mathrm{CR}$ & \\
\hline
\end{tabular}

Complication of transplanted patients

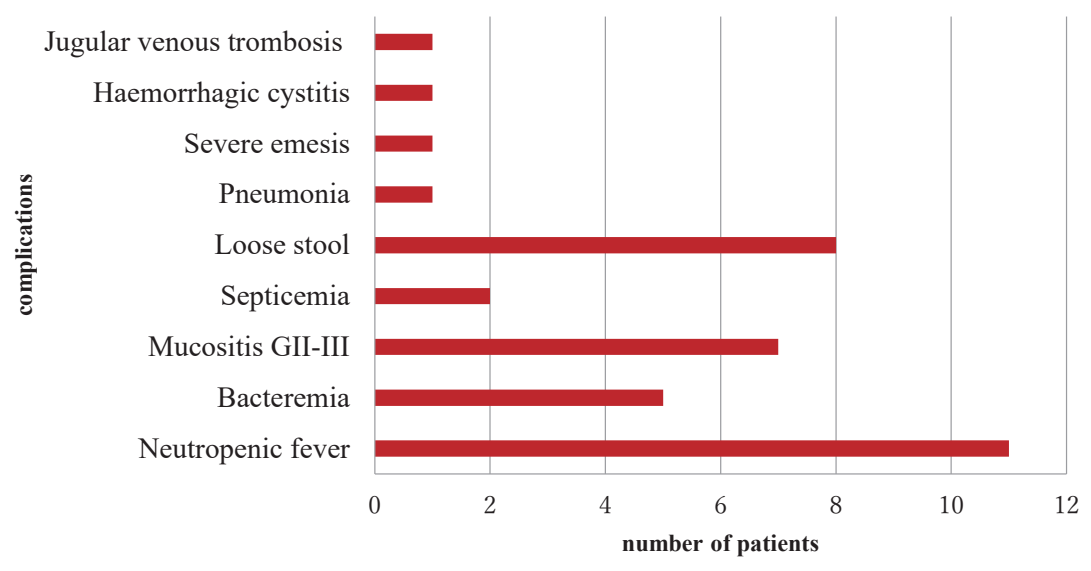

Figure 1. Complications of all patients

plant-related scientific and demographic data from various hospitals in the country in a synchronized and integrated way with the aim to document the total number of transplants done each year and for assessment of both short-term and long-term outcomes. The major challenges are a lack of appropriate software for keeping data and a lack of human resource training for doing this work.

\section{National marrow donor program}

Bangladesh has only recently stepped into the world of transplant. Prior to 2016, no allogeneic transplant had ever been done, but we will launch allogeneic HSCT in the near future. Currently, there is no voluntary national marrow donor registry. In March 2019, a proposal for organizing the Bangladesh Marrow Donor Registry (BMDR) was raised at a meeting observing the 5th year celebration of BMT in the country. The main challenges are human resource training and financing. Additionally, 


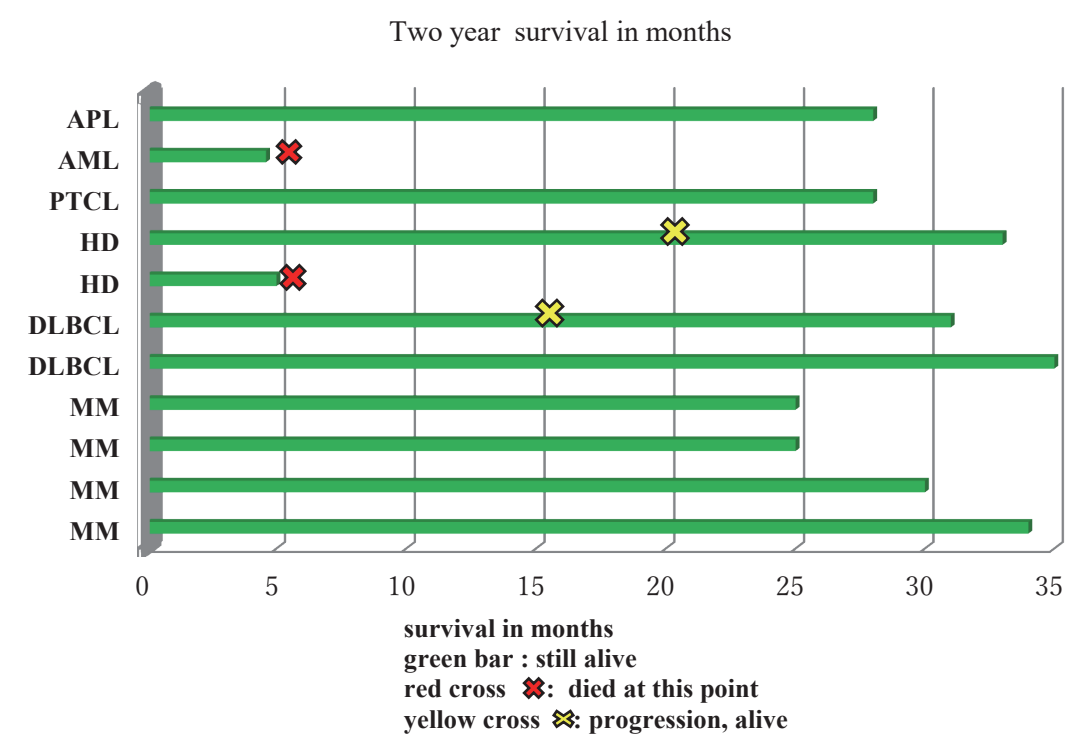

Figure 2. Outcomes of all transplant patients (the majority are alive with CR)

Table 2. Outcome at a glance over two years

\begin{tabular}{lll}
\hline \multicolumn{1}{c}{ Outcome } & \multicolumn{2}{c}{ Autologous transplant } \\
& \multicolumn{1}{c}{$\mathrm{N}=11$} & \multicolumn{1}{c}{ Remark } \\
\hline TRM in 100 days & $0 \%$ & \\
Complete remission/CR & $54.5 \%(6 / 11)$ & Alive with CR \\
Partial remission/PR & $9.1 \%(1 / 11)$ & Stable disease post-transplant \\
Relapse and alive & $18.2 \%(2 / 11)$ & On metronomic therapy \\
Relapse and died & $18.2 \%(2 / 11)$ & Death due to disease relapse \\
\hline
\end{tabular}

government support, public awareness, and the motivation to donate as an unrelated donor are other important challenges for our country.

\section{Essential qualifications for HSCT}

Being a developing country, our health budget is very limited and it is extremely difficult to allocate enough money for a transplant program. Consequently, financial constraints pose a major challenge for us. We must also secure trained physicians, technologists, and the logistical support necessary to run the program.

\section{International collaboration in Bangladesh}

The transplant program of DMCH was established as a joint collaboration between the Government of Bangladesh and the Massachusetts General Hospital (MGH) in Boston, MA, USA. Several physicians, technologists, and nurses of DMCH were trained by MGH staff from 20132014. Later, CMH developed transplant activity through collaboration with Tata Memorial in Kolkata, India.

\section{Discussion}

Over the past 10 years, Bangladesh has taken giant steps in healthcare and has made significant developments in the health sector. Key health indicators such as life expectancy and coverage of immunization have improved notably, while infant and maternal mortality rates have dropped significantly ${ }^{7}$. Several specialized hospitals for various fields have been built in recent years. As a consequence, the first bone marrow transplant unit in the country was established in the largest tertiary hospital, DMCH, and it has been running successfully since then. Later, two more centers started BMT programs. Here we have shared the country report of bone marrow transplant activities for 2016. Although the sample size is small and the indication for transplant is heterogeneous, the 2-year overall survival of $82.0 \%$ is truly encouraging.

As we are a developing country, we have to face a lot of challenges while operating in these centers. Most notably, BMT centers in tropical countries fight with the significant problem of unusual infections ${ }^{8}$. As a new center, the documented infection rate is $36.6 \%$, which is compa- 
rable to developed countries. The 100-day TRM remains $0 \%$, which is a testament to our commitment to performing transplant at its highest professional standard.

The health system of Bangladesh has been shaped to address the first generation of poverty-linked infectious, nutritional, infant, and maternity-related diseases, but given the epidemiological transition, the health system will have to be adjusted to fight with chronic non-communicable diseases, the most important being cancer'. In this context, establishing bone marrow transplant centers in a resource-limited country will surely address unmet medical needs.

\section{Conclusion}

The results in our transplanted patients are encouraging in terms of transplant-related complications, diseaserelated outcomes, and cost-effectiveness. In Bangladesh, a lack of public awareness about the existence of BMT programs, economic constraints, the absence of a health insurance system, and an inadequate allocation of funding have been identified as the main factors limiting the general population's access to this highly effective therapeutic strategy. As such, the data on BMT activity in 2016 shows slow progress in the number of transplants, but these centers will be capable of offering transplants, including allogeneic transplants, to a larger patient population in the near future if financial, logistical, and technical support are provided by the government to meet this demand.

\section{Acknowledgements}

The authors sincerely acknowledge the support of the Department of Hematology at DMCH, Apollo Hospitals Dhaka, and CMH Dhaka for providing the data from 2016. The transplant physicians, nurses, and additional staff of these three centers are gratefully acknowledged for their continuing efforts and dedication to transplant patients.

\section{Author's Contribution}

Manuscript was designed, drafted and edited by $\mathrm{Dr}$ Mafruha Akter. The manuscript was processed and reviewed by Prof MA Khan and Dr Bimolangshu R Dey.

\section{Conflict of Interest}

The authors declare no conflict of interest. Disclosure forms provided by the authors are available here.

\section{References}

1. Hossain MS, Iqbal MS, Khan MA, Rabbani MG, Khatun H, Munira S, et al. Diagnosed hematological malignancies in Bangladesh - a retrospective analysis of over 5000 cases from 10 specialized hospitals. BMC Cancer. 2014; 14: 438.

2. WHO/TIF Meeting on the Management of Haemoglobin Disorders (2007: Nicosia Cyprus). Management of haemoglobin disorders: report of a joint WHO-TIF meeting, Nicosia, Cyprus, 16-18 November 2007. World Health Organization, World Health Organization; 2018.

3. Mandal PK, Maji SK, Dolai TK. Present scenario of hemoglobinopathies in West Bengal, India: An analysis of a large population. Int J Med Public Health. 2014; 4: 496-9.

4. Yeh AC, Khan MA, Harlow J, Biswas AR, Akter M, Ferdous J, et al. Hematopoietic Stem-Cell Transplantation in the Resource-Limited Setting: Establishing the First Bone Marrow Transplantation Unit in Bangladesh. J Glob Oncol. 2018; 4: $1-10$.

5. Barron AM, Moran J, Nina SS, Harlow J, Gyawali M, Hossain F, et al. Building Specialized Nursing Practice Capacity in Bangladesh: An Educational Program to Prepare Nurses to Care for Oncology and Bone Marrow Transplant Patients in Dhaka, Bangladesh. J Glob Oncol. 2018; 4: 1-6.

6. Majhail NS, Mau LW, Denzen EM, Arneson TJ. Costs of autologous and allogeneic hematopoietic cell transplantation in the United States: a study using a large national private claims database. Bone Marrow Transplant. 2013; 48: 294-300.

7. Mahmood SAI. Health Systems in Bangladesh. 2012; 1: 1 .

8. Chandy M, Srivastava A, Dennison D, Mathews V, George B. Allogeneic bone marrow transplantation in the developing world: experience from a center in India. Bone Marrow Transplant. 2001; 27: 785-90.

9. Chowdhury AM, Bhuiya A, Chowdhury ME, Rasheed S, Hussain Z, Chen LC. The Bangladesh paradox: exceptional health achievement despite economic poverty. Lancet. 2013; 382: 1734-45.

https://doi.org/10.31547/bct-2019-006 Copyright (C) 2020 APBMT. All Rights Reserved. 